\title{
Coronary artery narrowing without irreversible myocardial damage or development of collaterals Assessment of "critical" stenosis in a human model
}

\author{
ERLING FALK \\ From the Institute of Pathology, Randers Centralsygehus, Denmark
}

SUMMARY Postinfarction cardiac rupture is the result of thrombotic occlusion of a functional end artery with no previous myocardial damage in the perfusion area of the occluded artery. The pre-existing atherosclerotic stenosis at the site of thrombosis is thus "non-critical" in relation to the development of collateral vessels and/or irreversible myocardial damage.

Eleven cases of postinfarction cardiac rupture were studie by microscopy of cross-sections of the thrombosed segments. At the site of the thrombosis, pre-existing atherosclerosis had narrowed the lumen to $11 \%$ or less of its normal cross-sectional area. Maximal pre-existing narrowing of the proximal left anterior descending artery was found in a case with $97 \%$ stenosis (histologically measured cross-sectional area reduction) and an estimated residual lumen of $0.71 \mathrm{~mm}^{2}$. The prestenotic luminal area which is usually considered angiographically as "normal" was in all cases shown histologically to be severely narrowed by a diffuse intimal thickening.

It is concluded that organic coronary stenosis must be far greater than $75 \%$ to be responsible for the development of collateral vessels and/or irreversible myocardial damage.

Coronary artery stenosis that limits blood flow below basal demands is usually considered critical. In human disease, however, the term "critical stenosis" is poorly defined, especially as no consistent relation has been documented between symptoms of ischaemic heart disease and the extent and severity of coronary narrowing. ${ }^{1-3}$ In addition, a severe stenotic lesion may be bypassed and adequately compensated by collateral vessels, which make evaluation of the ischaemic significance of the stenosis, per se, impossible. In animal studies, however, a critical level of stenosis has been identified. Isolated proximal coronary stenosis has to reduce the luminal cross-sectional area by about $95 \%$ before resting myocardial flow fails to meet the demand. ${ }^{45}$ At that degree of acute obstruction, the peripheral vascular bed is maximally dilated and further narrowing will cause myocardial ischaemia at rest.

At necropsy we are occasionally provided with a human model which is comparable with the experimental, isolated coronary stenosis. Thus it has previ-

The study was supported by a grant from Hjerteforeningen (The Danish Heart Foundation).

Accepted for publication 13 April 1982 ously been shown that a uniform patho-anatomical substrate exists in postinfarction cardiac rupture, consisting of an acute coronary occlusion with a recent myocardial infarct which is transmural and totally unprotected by scar or collateral vessels. ${ }^{6}$ Consequently, in these hearts we find acute occlusions of functional end arteries, and the pre-existing organic stenosis at the site of thrombosis can thus be considered "non-critical" in relation to the development of collateral vessels and/or irreversible myocardial damage.

This paper presents a quantitative assiessment of the pre-existing luminal narrowing in acutely thrombosed coronary arteries from 11 patients with postinfarction cardiac rupture.

\section{Subjects and methods}

Nine consecutive necropsy patients with heart rupture from Randers Hospital and two cases referred from another hospital in the same period (1 February 1980 to 30 June 1981) form the basis for this study.

After the heart was weighed the coronary arteries were gently flushed via the aorta with $100 \mathrm{ml} 4 \%$ formaldehyde solution and then a barium gelatine 
medium at $40^{\circ} \mathrm{C}$ was injected under a pressure of 150 $\mathrm{mmHg}$ maintained for 15 minutes. The medium was hardened by cooling and angiograms were taken in different projections. The heart was fixed for two weeks in a $4 \%$ formaldehyde solution, decalcified for three weeks in EDTA (ethylenediaminetetraacetic acid), and then stored for at least one week in formalin. The main coronary arteries and those of their branches thicker than $1 \mathrm{~mm}$ were cross-sectioned at 3 $\mathrm{mm}$ intervals. Each segment, angiographically shown to be stenosed or occluded, was processed for microscopy. All thrombosed segments were cross-sectioned at $200 \mu \mathrm{m}$ intervals and the point of maximal luminal reduction resulting from old atherosclerotic plaques was identified. The ventricular portion of the heart was cut into $1 \mathrm{~cm}$ thick slices parallel to the atrioventricular groove, photographed, and $x$-rayed, with each slice placed directly on the film. Several histological sections were prepared from the perfusion area of each coronary artery and from the myocardium adja- cent to the rupture.

\section{TISSUE SHRINKAGE}

To calculate the shrinkage that occurs when an artery is processed for microscopy the following experiment was performed. Unfixed segments of injected arteries were dissected free from the hearts, placed directly on radiographic film, and $x$-rayed. $X$-rays were repeated after fixation, dehydration, clearing, and embedding in paraffin. During this procedure and at the final microscopical examination of the histological sections it was observed that the shrinkage of the radio-opaque medium was equal to or a little more pronounced than the shrinkage of the artery lumen. The segments where the shrinkage of the $x$-ray medium equalled the luminal shrinkage were selected for measurements. The luminal diameters were measured on the radiographs and the luminal area shrinkage resulting from tissue processing was calculated. One-hundred and fifty measurements were done on 15 different vascular segments.

Table 1 Clinical data in 11 patients with postinfarction cardiac rupture

\begin{tabular}{|c|c|c|c|c|}
\hline Case No. & Age (y) & $\operatorname{Sex}$ & Survival ${ }^{\star}(d)$ & Preinfarction cardiac symptomst \\
\hline $\begin{array}{r}1 \\
2 \\
3 \\
4 \\
5 \\
6 \\
7 \\
8 \\
9 \\
10 \\
11\end{array}$ & $\begin{array}{l}82 \\
69 \\
69 \\
80 \\
71 \\
77 \\
79 \\
67 \\
74 \\
86 \\
68\end{array}$ & $\begin{array}{l}\mathbf{F} \\
\mathbf{M} \\
\mathbf{M} \\
\mathbf{M} \\
\mathbf{F} \\
\mathbf{M} \\
\mathbf{M} \\
\mathbf{M} \\
\mathbf{F} \\
\mathbf{M} \\
\mathbf{M}\end{array}$ & $\begin{aligned} & 1 \\
&< 1 \\
& 3<1 \\
&<1 \\
& 5 \\
&<1 \\
& 4 \text { weeks } \\
& 10 \text { weeks } \\
&<1 \\
&<1\end{aligned}$ & $\begin{array}{l}\text { None } \\
\text { Unstable angina } \\
\text { None } \\
\text { None } \\
\text { Unstable angina? } \\
\text { None } \\
\text { Unstable angina } \\
\text { None } \\
\text { Unstable angina } \\
\text { None } \\
\text { None }\end{array}$ \\
\hline
\end{tabular}

^Histological dating of the infarcts according to the criteria of Mallory et al. 9 †No patient had stable angina pectoris.

Table 2 Histological and angiographic data in 11 patients with postinfarction cardiac rupture

\begin{tabular}{|c|c|c|c|c|c|c|c|c|c|}
\hline \multirow{2}{*}{$\begin{array}{l}\text { Case } \\
\text { No }\end{array}$} & \multirow{2}{*}{$\begin{array}{l}\text { Heart } \\
\text { weight } \\
(g)\end{array}$} & \multirow{2}{*}{$\begin{array}{l}\text { Thrombosed } \\
\text { artery }\end{array}$} & \multirow{2}{*}{$\begin{array}{l}\text { Size of } \\
\text { perfusion } \\
\text { area }\end{array}$} & \multicolumn{3}{|c|}{ Measured histological areas } & \multicolumn{2}{|c|}{ Calculated stenoses } & \multirow{2}{*}{$\begin{array}{l}\text { True } \\
\text { residual } \\
\text { lumen }\left(\mathrm{mm}^{2}\right)\end{array}$} \\
\hline & & & & $\begin{array}{l}\text { Residual* } \\
\text { lumen } \\
\left(\mathrm{mm}^{2}\right)\end{array}$ & $\begin{array}{l}\text { Originalt } \\
\text { lumen } \\
\left(m m^{2}\right)\end{array}$ & $\begin{array}{l}\text { Prestenotic } \neq \\
\text { lumen } \\
\left(\mathrm{mm}^{2}\right)\end{array}$ & Angiographic $\$$ & Histological & \\
\hline $\begin{array}{r}1 \\
2 \\
3 \\
4 \\
5 \\
6 \\
7 \\
8 \\
9 \\
10 \\
11\end{array}$ & $\begin{array}{l}430 \\
450 \\
370 \\
490 \\
500 \\
450 \\
350 \\
600 \\
440 \\
385 \\
430\end{array}$ & $\begin{array}{l}\text { LAD (prox.) } \\
\text { LAD (prox.) } \\
\text { LM } \\
\text { LAD } \\
\text { LAD } \\
\text { R } \\
\text { LAD } \\
\text { LAD (prox.) } \\
\text { R } \\
\text { LAD } \\
\text { LAD }\end{array}$ & $\begin{array}{l}39 \% \\
42 \% \\
15 \% \\
20 \% \\
21 \% \\
37 \% \\
22 \% \\
43 \% \\
37 \% \\
22 \% \\
22 \%\end{array}$ & $\begin{array}{l}0.47 \\
1.30 \\
0.94 \\
1.07 \\
0.26 \\
0.47 \\
1.47 \\
0.51 \\
1.13 \\
0.55 \\
1.63\end{array}$ & $\begin{array}{l}17 \cdot 28 \\
15.08 \\
11.20 \\
13.66 \\
11.33 \\
12.53 \\
13.78 \\
24.62 \\
19.60 \\
13.17 \\
15.87\end{array}$ & $\begin{array}{r}7 \cdot 56 \\
7 \cdot 29 \\
2 \cdot 54 \\
4 \cdot 01 \\
5 \cdot 51 \\
6 \cdot 36 \\
4.32 \\
5 \cdot 18 \\
7 \cdot 29 \\
4 \cdot 12 \\
11 \cdot 92\end{array}$ & $\begin{array}{l}94 \% \\
82 \% \\
63 \% \\
73 \% \\
95 \% \\
93 \% \\
66 \% \\
90 \% \\
84 \% \\
87 \% \\
86 \%\end{array}$ & $\begin{array}{l}97 \% \\
91 \% \\
92 \% \\
92 \% \\
98 \% \\
96 \% \\
89 \% \\
98 \% \\
94 \% \\
96 \% \\
90 \%\end{array}$ & $\begin{array}{l}0.71 \\
1.95 \\
1.41 \\
1.61 \\
0.39 \\
0.71 \\
2.21 \\
0.77 \\
1.70 \\
0.83 \\
2.45\end{array}$ \\
\hline
\end{tabular}

Abbreviations: LAD, left anterior descending artery; (prox.) indicates that the occlusion is located proximal to the first diagonal branch; LM; left marginal branch; $R$, right coronary artery.

$\star$ Cross-sectional luminal area at maximal stenosis resulting from old atherosclerotic plaques.

+ Cross-sectional area encircled by the internal elastic membrane.

\# Cross-sectional luminal area of adjacent prestenotic segment which, angiographically, would be judged as "normal".

Residual lumen/prestenotic lumen.

i Residual lumen/original lumen.

$\star \star$ Residual lumen corrected for shrinkage caused by processing for microscopy (residual lumen $\times 3 / 2$ ). 

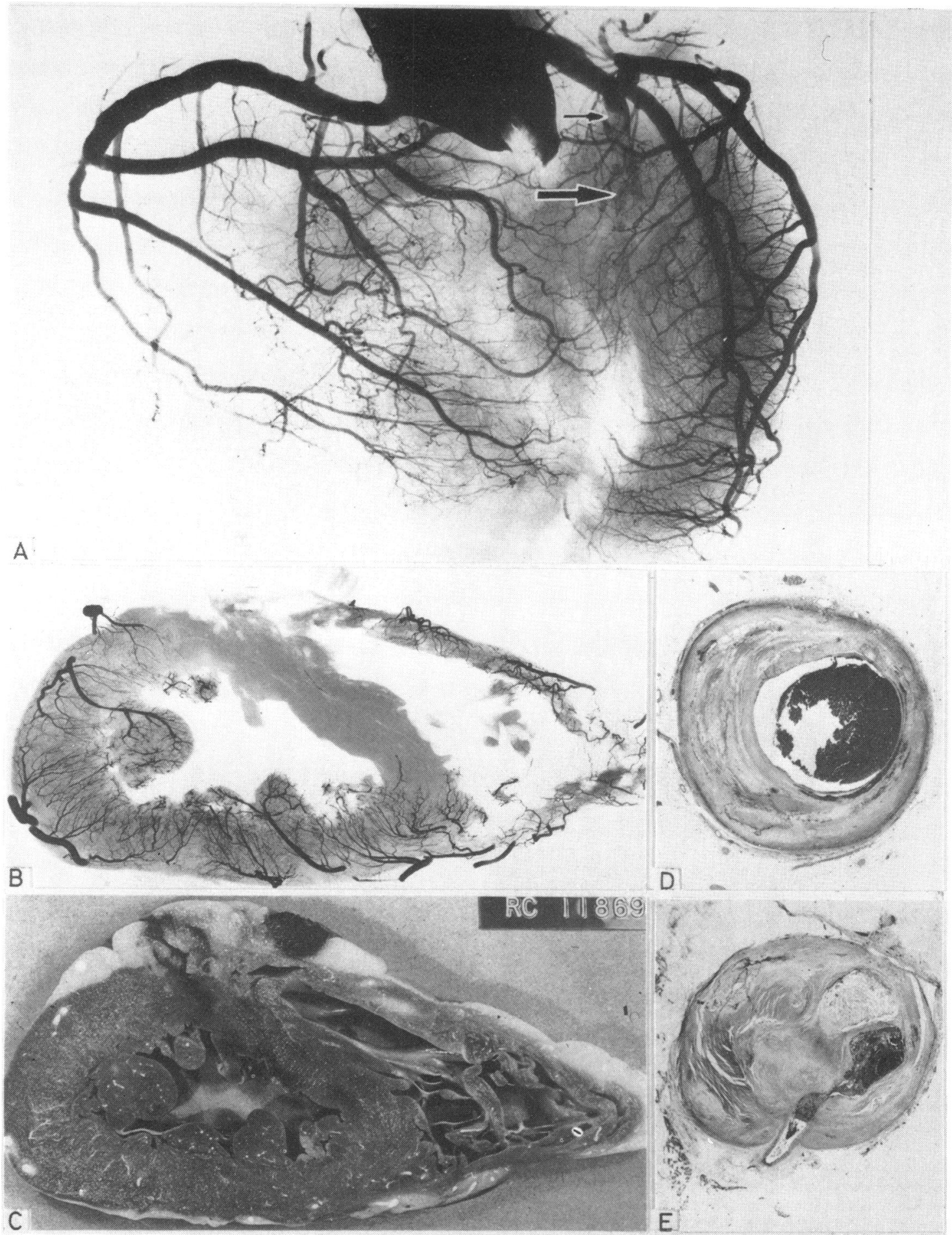

Fig. 1 Case 2 illustrating how severe a stenosis can be without collatral development or evidence of irreversible myocardial damage in the form of scar. (A) Postmortem angiogram in the anteroposterior view showing total occlusion of the proximal lefi anterior descending artery (thick arrow) without collateral distal filling of the vessel (original natural size). (B) Radiograph of a transverse myocardial slice showing no collateral vascular filling in the perfusion area of the left anterior descending artery (original natural size).

(C) Photograph of the same myocardial slice showing rupture of the anterior lefi ventricular wall. Microscopy showed anteroseptal infarction less than 1 day old; no myocardial fibrosis was present (original natural size). (D) Histological section from angiographic "normal" segment (thin arrow in A) showing diffuse intimal thickening with the lumen $64 \%$ obliterated (original magnification $\times 8$ ).

(E) Histological section showing occluding thrombus at the site of maximal atherosclerotic narrowing (thick arrow in $A$ ). This degree of old stenosis ( $91 \%$ cross-sectional area reduction) has not caused collateral development or produced irreversible myocardial damage in the form of fibrosis. In this case a histological area stenosis of $91 \%$ corresponds to an angiographic area stenosis of $82 \%$ (original magnification $\times 8$ ). 

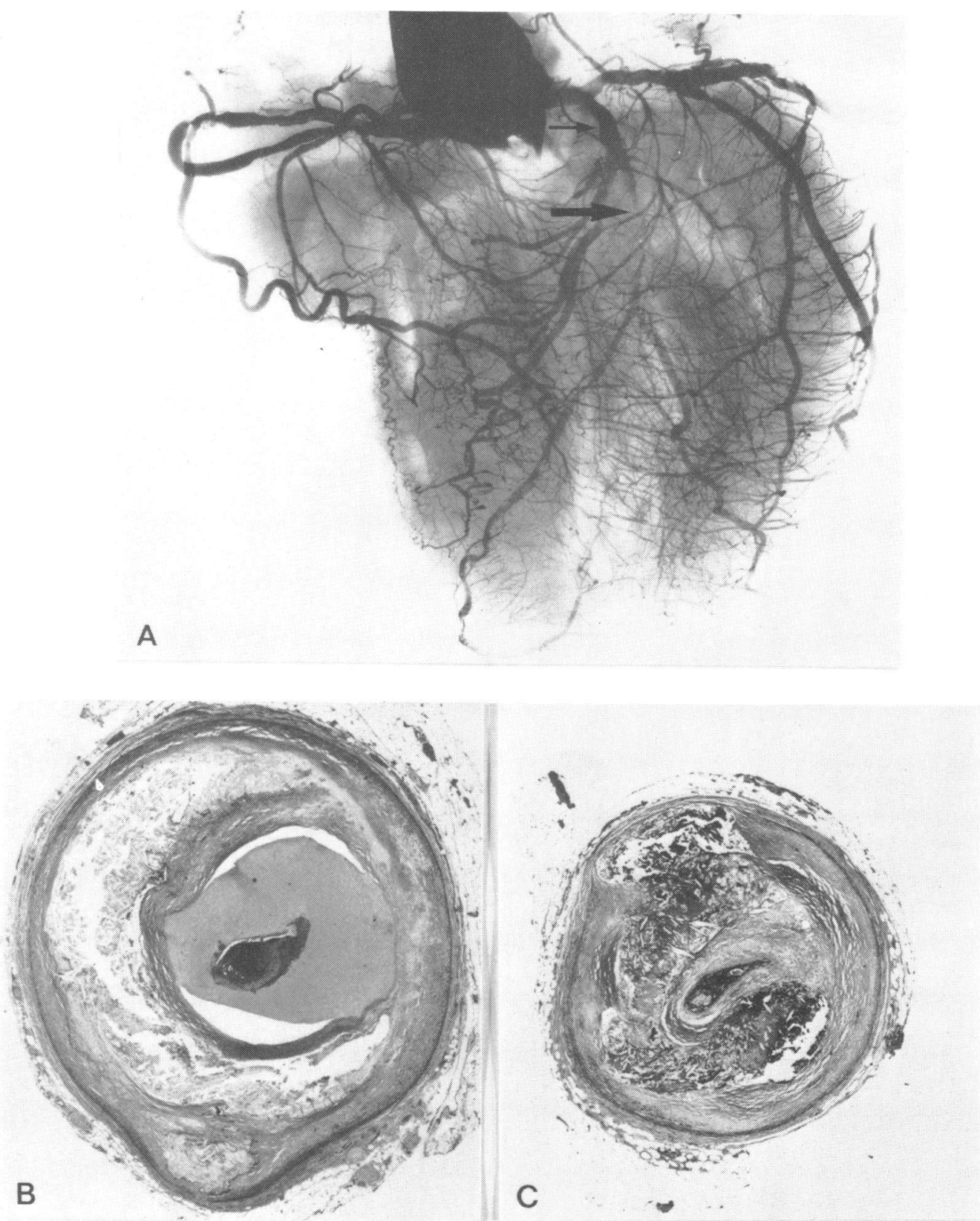

Fig. 2 Correlation of angiographic and pathological findings (case 5). (A) Angiogram showing total occlusion of lefi anterior descending artery (thick arrow) with poor collateral distal filling of the vessel (original natural size). (B) Histological section of the left anterior descending artery just after the bifurcation of the left main artery (thin arrow) where the vessel angiographically appears "normal" with a wide lumen. Nevertheless, the luminal narrowing resulting from diffuse atherosclerotic intimal thickening is $71 \%$ at that point. That is the reason why the real stenosis is consistently underestimated angiographically (original magnification $\times 14$ ).

(C) Histological section from the left anterior descending artery at the site of maximal stenosis resulting from old atherosclerotic plaques (thick arrow); the residual lumen is occluded by a recent thrombus. The histological area stenosis of $98 \%$ corresponds in this case to an angiographic area stenosis of $95 \%$ (original magnification $\times 14$ ). 


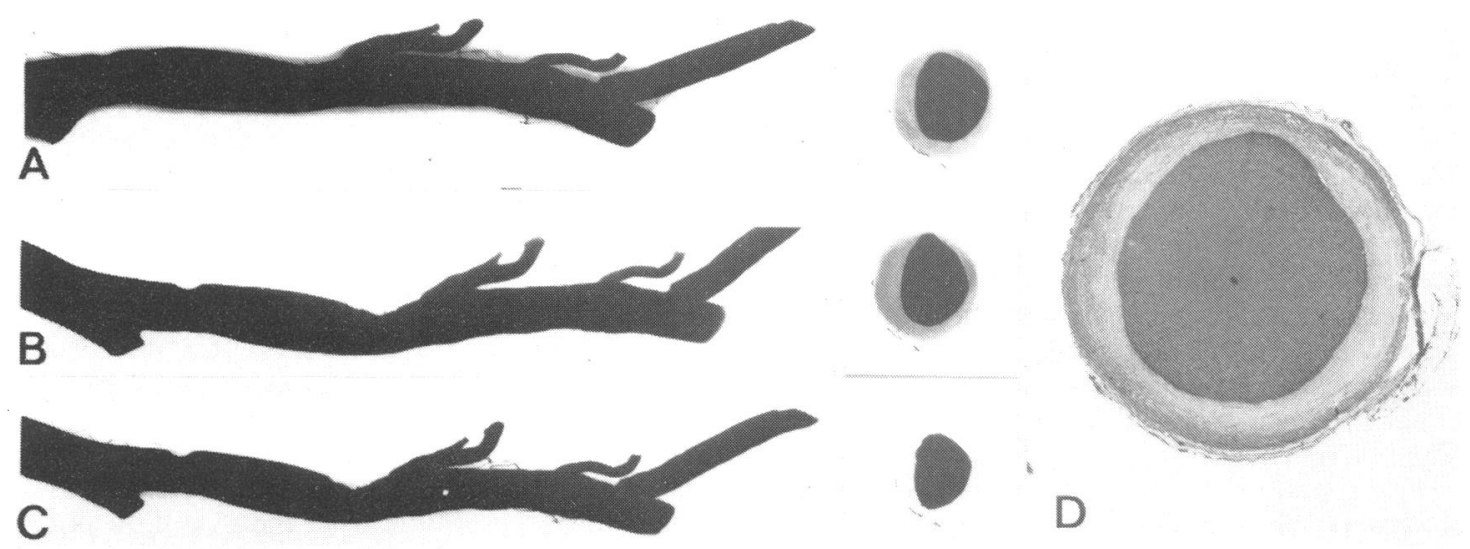

Fig. 3 Shrinkage of tissue and contrast medium caused by processing for microscopy. (A) Radiograph of an unfixed vascular segment placed directly on the $x$-ray film. (B) The same segment after fixation and decalcification. (C) The same segment after dehydration, clearing, and paraffin infiltration. That the shrinkage of the contrast medium equals the luminal shrinkage is shown by radiographs of corresponding cross-sections and by microscopy of the final histological sections $(D)$. The total shrinkage $(A$ to $C)$ results in a reduction of the luminal area to approximate two thirds of the original area of the unprocessed vessel. $((A),(B)$, and $(C)$ original magnification $\times 2 \cdot 5 ;(D)$ original magnification $\times 11)$ ).

\section{PERFUSION AREA}

The relative amount of ventricular myocardium supplied by the three large coronary arteries varies according to the anatomy of the coronary artery tree. The perfusion areas of the coronary arteries were identified from the angiograms, and the percentage of ventricular myocardium supplied by each artery was determined according to the results of Kalbfleisch and Hort. ${ }^{7}$ The perfusion area of the first diagonal branch was considered as large as that of the left anterior descending artery distal to the first diagonal branch. ${ }^{8}$

\section{DEFINITIONS}

Histological stenosis: the ratio between the crosssectional area of the residual lumen and the assumed original cross-sectional luminal area of the vessel at the point under consideration (the area encircled by the internal elastic membrane). All cross-sectional areas are calculated from measurements of maximal and minimal diameters assuming an elliptical crosssection (measured by projection microscopy using a Reichert Lanometer).

Angiographic stenosis: the ratio between the stenotic luminal area and the greatest prestenotic luminal area (which angiographically would be judged as "normal"). As the vessels in question are thrombosed and thus not visualised on the angiograms, the two areas had to be determined by microscopy of the histological sections.

\section{Results}

Clinical and pathological findings are summarised in Table 1 and 2.
Recent thrombi superimposed on atherosclerotic plaques were found in all patients, and the site of myocardial rupture corresponded with the point of arterial occlusion. At the site of the thrombus, all patients had histological stenosis of more than $89 \%$ caused by old atherosclerotic plaques. Apart from cases 8 and 9, the angiograms disclosed no collateral vessels bypassing the thrombotic occlusions (Fig. 1 and 2) and careful microscopical examination of the myocardium showed no fibrosis in the perfusion area of the thrombosed artery. Cases 8 and 9 hac ruptured ventricular aneurysms. The prestenotic segments which, on angiograms, are usually considered as "normal" were in all cases severely narrowed because of diffuse intimal thickening (confluent atherosclerotic lesions) (Fig. 1 and 2). Formalin fixation did not cause any significant tissue shrinkage (no difference between vessels dissected free and vessels in situ) but the subsequent tissue processing resulted in a reduction of the luminal area to approximate two-thirds of the original area of the unfixed vessel (median: $65 \%$, range: $50 \%$ to $74 \%$ ) (Fig. 3).

\section{Discussion}

Necropsy studies have shown that the infarction size is usually smaller than the perfusion area of the obstructed vessel $1^{10-12}$ and even cases of total coronary occlusion with no myocardial damage have been reported. ${ }^{11} 13$ The ability of collateral vessels to protect jeopardised myocardium is thus obvious. Therefore, to evaluate the ischaemic significance of organic stenoses, one has to identify stenotic lesions not bypassed by collateral vessels. But as many functional 
collateral vessels are below the resolution of modern cineangiographic equipment, ${ }^{14}$ in vivo determination of the human "critical stenosis" may be unreliable. The degree of coronary artery narrowing causing irreversible myocardial damage is thus poorly defined clinically. In fatal heart disease, however, the necropsy occasionally discloses postinfarction cardiac rupture, and in these cases the existence of significant collateral vessels can be excluded in the light of functional considerations, not merely because of inability to detect such vessels angiographically.

Thus, using a refined injection and dissection technique, Wessler et al. ${ }^{6}$ have shown that postinfarction cardiac rupture is the result of thrombotic occlusion of a functional end artery with no evidence of previous myocardial damage (fibrosis) in the perfusion area of the thrombosed artery. The reliability of their technique in showing collateral vessels in human hearts without coronary artery disease has been questioned 1516 but their method has been reliable in hearts with coronary occlusions. ${ }^{15}$ The present study was not undertaken to clear up the pathogenesis of postinfarction cardiac rupture, but our results are in agreement with the results of Wessler et al. Cases 8 and 9 are unusual cases of late myocardial rupture (ruptured aneurysms four and 10 weeks after the acute infarction) and the angiographically visible collateral vessels have probably developed secondarily to the thrombotic occlusions.

The aim of our study was to determine the maximal degree of old organic obstruction in the thrombosed coronary artery in cases of postinfarction cardiac rupture. These stenoses have not yet reached a degree that causes collateral development and/or irreversible myocardial damage.

Many pathologists consider an histological area stenosis of $75 \%$ as significant. ${ }^{1718}$ This study, however, shows that a pure organic stenosis far greater than $75 \%$ may be well tolerated. Thus, stenoses greater than $95 \%$ were observed without evidence of irreversible myocardial damage in the corresponding perfusion area.

Minor degrees of organic obstruction may of course be clinically significant in causing myocardial ischaemia and angina during exercise and, if vasoconstriction (spasm) is superimposed, even at rest. 1920

Histological stenosis is not comparable with angiographic stenosis. The pathologist compares the residual lumen with the presumed original lumen (area encircled by the internal elastic membrane) while the clinician compares the most narrowed segment with the adjacent "normal" arterial segment as depicted on the angiogram. The adjacent "normal" segment, however, is never normal, as the coronary arteries in ischaemic heart disease in addition to focal stenotic lesions have diffuse intimal thickening ${ }^{18}$ which often corresponds to a histological area reduc- tion of $75 \% .^{118}$ The result is that the angiographer compares stenotic segment with adjacent "norma 5 looking" but, nevertheless, narrowed segment, and the real degree of stenosis is thus consistently under $\overline{\bar{n}}$. estimated. To overcome this problem in angiographic-histological correlative studies, it is necessary to measure the stenotic residual lumen pre $\tilde{S n}^{-1}$ cisely and then to calculate the true size of the lumen $\overrightarrow{0}$ The clinician has to compensate for dimensionaterrors caused by angiographic magnification while the్ pathologist has to correct for postmortem alterationsand tissue shrinkage secondary to processing for microscopy. Our histological procedures resulted in anpo area reduction to two-thirds of the area of the unpro cessed vessel. This figure is in general agreement with the results obtained by measurements of volumes changes of whole organs and tissue specimens fixed in? formalin and processed for embedding ins paraffin. 2122

McMahon et al. ${ }^{23}$ have measured angiographically, the minimum cross-sectional lumen area in patients with unstable angina and proximal single vessel dis $\underline{\mathbb{}}$ ease without collateral vessels and found it $0.6 \mathrm{~mm}^{2}$ ( $92 \%$ cross-sectional area reduction). Our cases $1,6 \stackrel{\sim}{\infty}$ and 8 show proximal stenoses with a residual lumen of the same magnitude $\left(0.71,0.71\right.$, and $\left.0.77 \mathrm{~mm}^{2}\right)$. As alp stenoses in our cases are "non-critical", the presents study fully confirms the observation of McMahon et al. that a very severe coronary stenosis can be tolero ated in a functional end artery without irreversible myocardial damage in the perfusion area of the obö structed vessel. Stenotic coronary lesions with less than $90 \%$ angiographic diameter reduction can undoubtedly produce myocardial ischaemia and anginal pain during exercise, but from a haemodynamie point of view they are of moderate degree only, since they are practically never accompanied by angioge raphically visible collateral circulation. ${ }^{14} 24$ The pres ent pathological study confirms clinical observations that an organic stenosis has to be very severe to be held responsible for development of collateral vessels.응

The author thanks Drs Jens Vilhelm Thorborg and Jens Sand Kristensen for their help.

\section{References}

1 Roberts WC. The coronary arteries in fatal coronar events. In: Chung EK, ed. Controversy in cardiology. Net York, Heidelberg, Berlin: Springer-Verlag, 1976: 1-22థ

2 Proudfit WL, Shirey EK, Sones FM Jr. Distribution of arterial lesions demonstrated by selective cinecoronarp arteriography. Circulation 1967; 36: 54-62.

3 Rafflenbeul W, Urthaler F, Lichtlen P, James TND Quantitative difference in "critical" stenosis between 
right and left coronary artery in man. Circulation 1980 62: 1188-96.

4 Gould KL, Lipscomb K, Hamilton GW. Physiologic basis for assessing critical coronary stenosis. Am $\mathcal{F}$ Cardiol 1974; 33: 87-94.

5 Gregg DE, Dedynek JL. Compensatory changes in the heart during progressive coronary artery stenosis. In: Maseri A, Klassen GA, Lesch M, eds. Primary and secondary angina pectoris. New York: Grune \& Stratton, 1978: 3-11.

6 Wessler S, Zoll PM, Schlesinger MJ. The pathogenesis of spontaneous cardiac rupture. Circulation 1952; 6: 334-51.

7 Kalbfleisch $\mathrm{H}$, Hort W. Quantitative study on the size of coronary artery supplying areas postmortem. Am Hear $\mathcal{f}$ 1977; 94: 183-8.

8 Hori $M$, Inoue $M$, Ohgitani $N$, et al. Site and severity of coronary narrowing and infarct size in man. Br Heart $\mathcal{F}$ 1980; 44: 271-9.

9 Mallory GK, White PD, Salcedo-Salgar J. The speed of healing of myocardial infarction. Am Heart $\mathcal{f} 1939$; 18: 647-71.

10 Jones AM. The functional role of intercoronary anastomoses. Acta Cardiol (Brux) 1965; 11, suppl: 130-44.

11 Baroldi G. Functional morphology of the anastomotic circulation in human cardiac pathology. In: Bajusz E, Jasmin G, eds. Methods and achievements in experimental pathology. vol. 5. Functional morphology of the heart. Basel: Karger, 1971: 438-73.

12 Lee JT, Ideker RE, Reimer KA. Myocardial infarct size and location in relation to the coronary vascular bed at risk in man. Circulation 1981; 64: 526-34.

13 Blumgart HL, Schlesinger MJ, Zoll PM. Angina pectoris, coronary failure and acute myocardial infarction. YAMA 1941; 116: 91-7.

14 Gensini, GG, Bruto da Costa BC. The coronary collateral circulation in living man. Am f Cardiol 1969; 24: 393400.
15 Rodriguez FL, Robbins SL. Postmortem angiographic studies on the coronary arterial circulation. Am Hean $\mathcal{f}$ 1965; 70: 348-64.

16 Cohen MV. The functional value of coronary collaterals in myocardial ischemia and therapeutic approach to enhance collateral flow. Am Heart f 1978; 95: 396-404.

17 Davies MJ, Woolf N, Robertson WB. Pathology of acute myocardial infarction with particular reference to occlusive coronary thrombi. Br Heart $\mathcal{F}$ 1976; 38: 659-64.

18 Arnett EN, Isner JM, Redwood DR, et al. Coronary artery narrowing in coronary heart disease: comparison of cineangiographic and necropsy findings. Ann Intern Med 1979; 91: 350-6.

19 Maseri A. Pathogenetic mechanisms of angina pectoris: expanding views. Br Heart $\mathcal{F}$ 1980; 43: 648-60.

20 MacAlpin RN. Relation of coronary arterial spasm to sites of organic stenosis. Am $\mathcal{F}$ Cardiol 1980; 46: 143-53.

21 Baker JR. Principles of biological microtechnique. London: Methuen, 1958: 75-86.

22 Bahr GF, Bloom G, Friberg U. Volume changes of tissues in physiological fluids during fixation in osmium tetroxide or formaldehyde and during subsequent treatment. Exp Cell Res 1957; 12: 342-55.

23 McMahon MM, Brown BG, Cukingnan R, et al. Quantitative coronary angiography: measurement of the "critical" stenosis in patients with unstable angina and single-vessel disease without collaterals. Circulation 1979; 60: 106-13.

24 Levin DC, Kauff M, Baltaxe HA. Coronary collateral circulation. $A \mathcal{F}$ 1973; 119: 463-73.

Requests for reprints to Dr Erling Falk, Institute of Pathology, Aalborg sygehus, Nord, DK-9000 Aalborg, Denmark. 